\title{
When and how does anger during goal pursuit relate to goal achievement? The roles of persistence and action planning
}

\author{
Antje Schmitt ${ }^{1}\left[\right.$ Michael M. Gielnik ${ }^{2} \cdot$ Sebastian Seibel $^{3}$
}

Published online: 13 August 2018

(c) The Author(s) 2018

\begin{abstract}
Anger is a fundamental negative activating state that may occur in the process of goal pursuit when goals are blocked or frustrated. We investigate when and why anger during goal pursuit may positively or negatively relate to goal achievement. Drawing upon action regulation theory and the literature on affective consequences, we develop and test a moderated mediation model in which persistence functions as a mediator of the relationship between anger and goal achievement and this mediation is moderated by action planning. We tested the model in two correlational field studies (Study 1, $N=197$; Study 2, $N=110$ ). Our analyses supported the general model. Across both studies, self-reported anger during goal pursuit is negatively related to later goal achievement through a decrease in persistence when participants' action planning is low. When action planning was reported to be high, anger was unrelated to persistence and goal achievement. Our results highlight the value of integrating action regulatory processes when discussing the relationships between affective states and goal achievement.
\end{abstract}

Keywords Goals $\cdot$ Anger $\cdot$ Action planning $\cdot$ Goal achievement $\cdot$ Persistence

\section{Introduction}

Think about a time when you set a personal or professional goal to be reached within a few days. Imagine further that during goal pursuit, a feeling of anger arose, for instance, because you were interrupted by others or because you were prevented from engaging in the goal by some external barriers. Was your angry reaction during goal pursuit functional or dysfunctional for goal achievement? More specifically, why and when did the feeling of anger during goal pursuit relate to goal achievement? We focus on persistence in goal pursuit as a core mechanism that links anger and goal achievement, and set action planning as a boundary condition that might help in answering these questions.

Antje Schmitt

a.schmitt@rug.nl

1 Department of Psychology, Faculty of Behavioural and Social Sciences, University of Groningen, Grote Kruisstraat 2/1, 9712 TS Groningen, The Netherlands

2 Institute of Strategic HR Management, Research and Development, Leuphana University of Lüneburg, Lüneburg, Germany

3 Institute of Psychology, Otto-Friedrich University of Bamberg, Bamberg, Germany
There are divergent perspectives on the link between anger arising from inappropriate goal progress and persistence during goal striving. On the one hand, anger is a discrete and activating affect that elicits behavioral approach tendencies (Carver and Harmon-Jones 2009; Maglio et al. 2014) that are conducive to persistence. On the other hand, some research reveals that when individuals experience anger this may create an off-task focus such that they have to focus their attention on coping with the negative emotion (Beal et al. 2005; Ellis and Ashbrook 1988; Seo et al. 2004). Accordingly, anger might reduce persistence when people are mentally engaged in managing the anger-eliciting situation. This, in turn, may have detrimental consequences for individuals' goal attainment.

In the current study, we apply and integrate the different perspectives on the functional and dysfunctional consequences of anger arising from inappropriate goal progress on persistence and goal achievement. Specifically, we argue for the importance of psychological action planning as a boundary condition (Frese and Keith 2015). We assume that the generation of action plans helps people to guide goaldirected behavior and activities (Frese et al. 2007; Frese and Zapf 1994; Parke et al. 2018; Zacher and Frese 2018) and to use the energy and approach motivation provided by anger to direct them towards a set goal. This, in turn increases the 


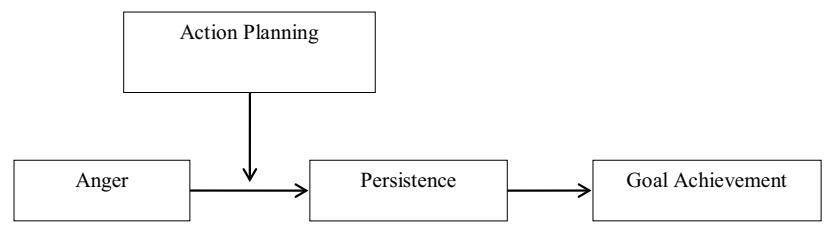

Fig. 1 Research model

likelihood of constructive goal-oriented behavior following anger. When action planning is low, however, people are less likely to use their anger to engage in persistent and goaloriented behavior. Our research model is depicted in Fig. 1. We provide correlational evidence by testing our hypotheses in two field studies based on heterogeneous samples of students and employees in order to cross-validate our findings.

\section{Anger in the process of goal pursuit and goal achievement: persistence as a mediator}

Anger is a discrete negative affective experience that is described as highly activating (Carver and Harmon-Jones 2009; Watson et al. 1999). We focus on anger as an achievement-related emotion that which relates to the personal achievement of goals or outcomes (Pekrun et al. 2006) and may emerge from the experience of obstacles during goal pursuit (Beal et al. 2005; Berkowitz and Harmon-Jones 2004; Gibson and Callister 2010). Anger arises when goals are blocked or frustrated such that people are prevented from attaining a goal by external barriers or an external agent's behavior that is perceived as inadequate (Beal et al. 2005; Berkowitz and Harmon-Jones 2004; Gibson and Callister 2010; Maglio et al. 2014; Ohly and Schmitt 2015). Anger may also be experienced when the person himself or herself is responsible for the aversive event or when the cause is ambiguous and cannot be attributed to a specific barrier or person (Kuppens and Tuerlinckx 2007; Mikulincer 1988).

Previous research suggests that a negative activating affect, such as anger arising from inappropriate goal progress, may relate to goal achievement by affecting individuals' persistence during goal pursuit (Lench and Levine 2008; Seckler et al. 2017). Persistence is one of the main characteristics of human motivation (Kanfer et al. 2008; O'Shea et al. 2017). It refers to whether a person maintains or changes the duration and the path of the action directed at attaining a goal. Being persistent means that people invest a high amount of resources such as time and energy in their endeavor to pursue a certain goal, despite the potential problems or barriers that may occur in the process of goal pursuit (Frese and Fay 2001; Seo et al. 2004). Persistence is positively related to goal achievement (Frese and Fay 2001; Kanfer et al. 2008; Locke and
Latham 1990), it has, however, generally received less attention in motivational and self-regulation research in comparison to the motivational dimensions of direction and intensity (Kanfer et al. 2008; Locke and Latham 1990; O'Shea et al. 2017).

Anger arising from inappropriate goal progress may promote individuals' persistence during goal pursuit (Lench and Levine 2008; Seckler et al. 2017). Based on the feelings-as-information model (Schwarz and Clore 1983, 2003), affective states signify whether or not a person has performed adequately. Being angry signals a problematic situation indicating a gap between the desired and the present situation. In line with the cybernetic model of self-regulation (Carver and Scheier 1998), anger indicates a discrepancy which guides action towards its reduction. This may result in the investment of energy toward the accomplishment of an action or task (Carver 2006; Rucker and Petty 2004). Another line of reasoning is that anger may increase persistent behavior to elicit a more positive affective state or to avoid an increase in anger in the future (Baumeister et al. 2007). Behavioral choices about persistence can be motivated by the idea that feelings of anger can be repaired such that individuals anticipate feeling better after persistence has been shown (Baumeister et al. 2007; Seckler et al. 2017).

However, other research suggests that when people experience anger they easily detract from the goal to be met because they tend to address and minimize the source of this affective state (e.g., obstacles that impede goal progress such as the inappropriate behavior of other people). Focusing on and managing the anger-eliciting situation draws on finite working memory capacity resources and thus depletes cognitive and energetic resources and these in turn cannot be invested in engaging in the goal (Beal et al. 2005; Kanfer et al. 1994, 2008). Accordingly, anger might reduce persistence while working on a goal when people are mentally engaged in managing and coping with the anger situation. This may lead to detrimental consequences for individuals' goal attainment (Frese and Keith 2015; Seo et al. 2004).

Furthermore, anger is also linked to displeasure as it signals a potential threat (Aarts et al. 2010). This may, in turn, elicit avoidance reactions (Watson et al. 1999) and, as a consequence, lead to low levels of persistence and engagement toward a certain goal. Similarly, there is research showing that people in negative affective states such as anger may think that the current course of action will not be successful in order to attain the corresponding goal (cf., Aarts et al. 2010), which leads to a revision of one's strategy of goal attainment, and thus, reduces persistent goal striving (Frese and Keith 2015). In the current study, we propose that whether anger is positively or negatively related 
to persistence in goal pursuit and to goal achievement, is dependent on the role of action planning.

\section{Action planning as a boundary condition}

Action regulation theory (Frese and Zapf 1994) states that human action is goal-oriented behavior that unfolds in a sequence: the action sequence starts with the generation of a goal and people then have to process and collect information about their environment, plan how to reach the goal, monitor the execution of action plans, and process feedback that may help them to attain their goal (Frese et al. 2007; Frese and Zapf 1994; Zacher and Frese 2018). Accordingly, action plans are particularly important for converting goals into action (Frese et al. 2007; Parke et al. 2018). They are characterized as mental simulations of actions as they refer to individuals' cognitive representations about the sequence of steps necessary to achieve a goal (Frese and Zapf 1994; Gielnik et al. 2014; Zacher and Frese 2018). Research suggests that it is not the quantity of planning that is critical but the quality of action planning that is more important for effective action regulation (Frese et al. 2007). The quality of plans can be described by whether or not plans refer to a long-range perspective such that they are formulated with regard to future opportunities and potential hindrances, by their degree of detailedness of sub-steps leading to goal achievement, and by the generation of back-up plans (Frese et al. 2007; Frese and Zapf 1994). Research has provided evidence of the beneficial consequences of action planning for performance-related outcomes (for an overview see Gollwitzer 1999). Furthermore, action planning is of fundamental importance for regulating one's actions during goal pursuit. Planning helps individuals to stay on track and to ensure that a certain goal is not lost or forgotten. Action plans increase the likelihood of overcoming procrastination such that it becomes easier for individuals to readdress or maintain their goal-oriented behavior (Diefendorff and Lord 2003).

\section{The present studies}

We aim to extend this line of research on the beneficial consequences of action planning. We argue that action planning functions as a boundary condition that determines whether anger during goal pursuit translates into persistence and, consequently, goal achievement. We build our idea on action regulation theory (Frese and Zapf 1994; Zacher and Frese 2018) and the perspective of planning functioning as forethought and prospection (Baumeister et al. 2016; Lebel 2017; Lerner and Tiedens
2006). According to this perspective, planning builds on prospective thinking such that people use anticipated opportunities and happenings as a guide for current behavior (Baumeister et al. 2016; Parke et al. 2018).

We argue that action planning functions as a guide for people and may aid them in keeping their attention and motivation focused on on-task behaviors and not getting distracted by their feelings of anger. When people experience anger during goal pursuit and have generated a strong action plan, this might help them to direct their motivational resources towards focusing on future aspects, thus directing behavior toward key activities in the goal achievement process (Baumeister et al. 2016; Frese and Gielnik 2014; Parke et al. 2018). When a strong feeling of anger is combined with action planning, it should help individuals to keep on or return to a mode of goal-related action. In consequence, the likelihood to engage in persistent behavior following anger should increase.

In contrast, a strong feeling of anger may reduce persistence if people have not generated a detailed and future-oriented action plan. When anger is experienced, it requires a significant amount of regulatory resources that may interfere with a task or goal (Beal et al. 2005). Without planning, there is a lack of orientation, structure, control, and guidance, thereby making it more difficult for people to maintain their mode of action, mobilizing effort, and trying to accomplish their goals in times when anger during goal pursuit arises (Bhanji and Delgado 2014; Lebel 2017; Parrott 2001). Hence, individuals, who have not generated detailed and future-oriented plans in advance, might have more difficulties in persistently pursuing and accomplishing their goals (Lebel 2017; Parrott 2001). Also, when anger during goal pursuit is low (e.g., obstacles to goal attainment are not experienced), the guiding aspect of action planning in terms of its regulatory function is less needed for goal-directed persistent behavior to be shown and, consequently, less important for goal achievement.

In sum, we argue that the relationship between anger, persistence, and goal achievement is determined by the level of action planning. First, we assume that action planning moderates the relationship between anger and persistence such that the relationship is positive for high levels of action planning and negative for low levels of action planning (Hypothesis 1). Second, we hypothesize that action planning moderates the indirect effect of anger on goal achievement through persistence. More specifically, anger is positively related to goal achievement through persistence when the level of action planning is high. Anger is negatively related to goal achievement trough persistence when the level of action planning is low (Hypothesis 2). 
To investigate the proposed relationships, we conducted two field studies. In Study 1, we tested our hypotheses based on a heterogeneous sample of students and employees. Study 2 was aimed at cross-validating the results by using a different measure of action planning.

\section{Study 1}

\section{Method}

\section{Procedure and sample}

A field study design with two measurement waves was applied to test our hypotheses. We used a convenient sample and invited people through personal contacts to participate in the study. At Time 1 (T1), 210 participants provided complete data. The participants were re-contacted 1 week later to fill in a follow-up survey. The final sample of respondents who completed both surveys consisted of 209 individuals. Of the participants 133 were students, 70 were employees, and six respondents did not report their employment status. Of our participants, 109 (52.7\%) were male. Two participants did not report their gender. Mean age was 28.35 years $(S D=10.68)$. In terms of highest educational degree achieved, two participants had a general education degree, 15 had a middle school degree, 50 had a high school degree, 99 had a Bachelor's degree, 39 had a Master's degree, and three held a Ph.D. One participant did not report his or her educational level. The respondents did not receive anything in return for their participation.

\section{Measures}

At $\mathrm{T} 1$, the participants were asked to report and briefly describe one personal goal that they intended to achieve within the next 7-14 days. The participants were asked to mention any type of goal related to the work or non-work domain, or a goal related to their studies. For instance, people reported goals such as "To find a job in the next 14 days", "Organizing a workshop", "Finalizing a written assignment", "Finishing a work project", "Moving houses". The following items referred to their respective goals.

Action planning: At T1, the participants were asked to answer the following questions in an open-question format: "What is your plan to achieve the goal? What are your next steps? What do you want to do when, where and how? Is there anything else you want to do to achieve the goal?". The degree and quality of action planning was rated by two independent research assistants who were blind to the hypotheses. We developed a coding scheme based on Frese et al. (2007). Participants' answers were rated and coded as high in action planning when their plan was based on a long-range perspective such that participants anticipated the future and planned ahead by implementing strategies to control the environment at present in order to assure goal attainment in the future. Answers were rated as moderately high in action planning when the plan contained a few thoughts about potential future opportunities and prospective future steps. Answers were considered low in action planning when the plan was very reactive and passive such that respondents decided to wait and see what happens (Frese et al. 2007). We calculated intraclass coefficients as parameters of item reliabilities for the two raters. The inter-rater reliability for the two raters was high $(\mathrm{ICC}=0.894)$ (Shrout and Fleiss 1979).

Anger was measured at T1 with the single item "To what extent does the following statement apply to you?: When I think of what I have achieved with regard to my goal so far, I feel angry." The item was answered on a 5-point scale ranging from 1 (does not apply at all) to 5 (fully applies).

Goal achievement was measured at T1 and Time 2 (T2) with the single item "On a scale from 0 to $100 \%$, how much of the goal have you already achieved?" (Sheldon and Elliot 1998). We used the item at T1 as a baseline measure and goal achievement at T2 as our dependent variable. In our statistical analyses, we controlled for the baseline measure to model change in the dependent variable.

Persistence was measured at T2 with two items: "To what extent did you persistently pursue your plan to reach your goal in the last week?" and "To what extent did you stick to your plan on how to achieve your goal when difficulties occurred in the last week?". The items were answered on 5-point scales ranging from 1 (not at all) to 5 (very much). The two items were strongly correlated $(\rho=0.59, p<0.001)$ as indicated by calculations based on the Spearman-Brown formula (Eisinga et al. 2013).

Demographic control variables: At T1, we controlled for age and employment status ( $1=$ student, $2=$ employee) to account for the heterogeneous background of our sample.

\section{Data analysis}

To test our hypotheses, we used the PROCESS macro for SPSS (Hayes 2013). PROCESS can be applied for pathanalysis to test our moderation hypothesis and it estimates conditional indirect effects as well as bootstrap confidence intervals. PROCESS requires data to be complete. Accordingly, 12 cases with missing data on any of the variables were deleted in the regression analyses based on listwise deletion. Unstandardized regression coefficients were produced and variables that were used to form the interaction term (i.e., anger, action planning) were mean-centered by PROCESS prior to calculating their product (Hayes 2013). Furthermore, we mean-centered the control variables to ease the interpretation of the coefficients. We examined 
Table 1 Means (M), standard deviations (SD), and correlations of Study 1 variables

\begin{tabular}{|c|c|c|c|c|c|c|c|c|c|}
\hline & & $M$ & $S D$ & 1 & 2 & 3 & 4 & 5 & 6 \\
\hline 1 & Age & 28.35 & 10.68 & - & & & & & \\
\hline 2 & Employment status & 1.34 & 0.48 & $0.57 * *$ & - & & & & \\
\hline 3 & Anger T1 & 2.10 & 1.15 & -0.10 & -0.09 & - & & & \\
\hline 4 & Action planning T1 & 1.26 & 0.46 & 0.07 & 0.05 & -0.13 & - & & \\
\hline 5 & Goal achievement T1 (\%) & 42.64 & 25.98 & 0.04 & 0.04 & $-0.16^{*}$ & -0.03 & - & \\
\hline 6 & Persistence T2 & 3.34 & 0.95 & $0.24 * *$ & $0.14 *$ & $-0.18 *$ & 0.05 & $0.28 * *$ & - \\
\hline 7 & Goal achievement T2 (\%) & 68.64 & 27.90 & 0.12 & 0.05 & $-0.19 * *$ & 0.01 & $0.56^{* *}$ & $0.55 * *$ \\
\hline
\end{tabular}

$N=197-209$. Employment status was coded $1=$ student, $2=$ employee

$T$ Time

${ }^{*} p<0.05 ; * * p<0.01$

Table 2 Results of the conditional indirect effect hypothesis as based on conditional process analysis (Study 1)

\begin{tabular}{|c|c|c|c|c|c|}
\hline Predictor variable & $B$ & $S E$ & $95 \% C I$ & $t$ & $p$ \\
\hline \multicolumn{6}{|c|}{ DV: persistence T2 (mediator variable model) } \\
\hline Age & 0.02 & 0.01 & 0.01 to 0.04 & 2.91 & 0.004 \\
\hline Employment status & 0.01 & 0.16 & -0.31 to 0.32 & 0.03 & 0.974 \\
\hline Goal achievement $\mathrm{T} 1$ & 0.01 & 0.00 & 0.00 to 0.01 & 3.69 & 0.000 \\
\hline Anger T1 & -0.05 & 0.06 & -0.16 to 0.07 & -0.82 & 0.416 \\
\hline Action planning $\mathrm{T} 1$ & 0.14 & 0.14 & -1.36 to 0.43 & 1.01 & 0.312 \\
\hline Anger $\mathrm{T} 1 *$ action planning $\mathrm{T} 1$ & 0.40 & 0.16 & 0.10 to 0.71 & 2.60 & 0.010 \\
\hline$R^{2}$ & 0.166 & & & & \\
\hline \multicolumn{6}{|c|}{ DV: goal achievement T2 (dependent variable model) } \\
\hline Age & 0.07 & 0.17 & -0.29 to 0.38 & 0.40 & 0.689 \\
\hline Employment status & -3.13 & 3.70 & -10.42 to 4.15 & -0.85 & 0.399 \\
\hline Goal achievement $\mathrm{T} 1$ & 0.47 & 0.06 & 0.36 to 0.59 & 8.11 & 0.000 \\
\hline Anger T1 & -1.14 & 1.30 & -4.23 to 1.09 & -0.88 & 0.382 \\
\hline Persistence T2 & 11.81 & 1.64 & 8.58 to 15.04 & 7.21 & 0.000 \\
\hline$R^{2}$ & 0.476 & & & & \\
\hline Action planning & Uns & ndirect effect & Boot $S E$ & Boot LLCI & Boot ULCI \\
\hline \multicolumn{6}{|c|}{$\begin{array}{l}\text { Conditional indirect effect at action plan- } \\
\text { ning }=25 \text { th and } 75 \text { th percentiles }\end{array}$} \\
\hline 25 th percentile & -1 & & 0.87 & -3.39 & -0.05 \\
\hline 75th percentile & & & 0.93 & -1.10 & 2.59 \\
\hline
\end{tabular}

Listwise $N=197$. Unstandardized coefficients are reported. Variables that are used to calculate the interaction term (i.e., anger, action planning) were mean-centered prior to analysis. Bootstrap sample size $=5000$

$T$ time, $D V$ dependent variable

the conditional indirect effects such that the relationships between anger, persistence, and goal achievement were tested at the 25th and the 75th percentiles of action planning (Dawson and Richter 2006; Hayes 2013).

\section{Results and discussion}

Descriptive statistics and inter-correlations of the variables are presented in Table 1 . Anger at T1 was negatively related to persistence at $\mathrm{T} 2(r=-0.18, p<0.05)$ as well as to goal achievement at T1 $(r=-0.16, p<0.05)$, and T2 $(r=-0.19$, $p<0.01)$. Persistence at $\mathrm{T} 2$ and goal achievement at $\mathrm{T} 2$ were positively related $(r=0.55, p<0.01)$. Action planning was not significantly related to any of the other variables.

Hypothesis 1 states that planning moderates the relationship between anger and persistence. The results show that the interaction term is significant $(B=0.40, S E=0.16$, $p=0.010$ ) (Table 2, upper part). The increase of $R^{2}$ in persistence due to the interaction was $3.00 \%(F=6.75, p=0.010)$. The significant interaction effect is depicted in Fig. 2. We conducted a simple slopes analysis (i.e., tested whether the slopes are significantly different from zero) to facilitate 
Fig. 2 Two-way interaction of anger Time 1 and action planning Time 1 on persistence Time 2 (Study 1)

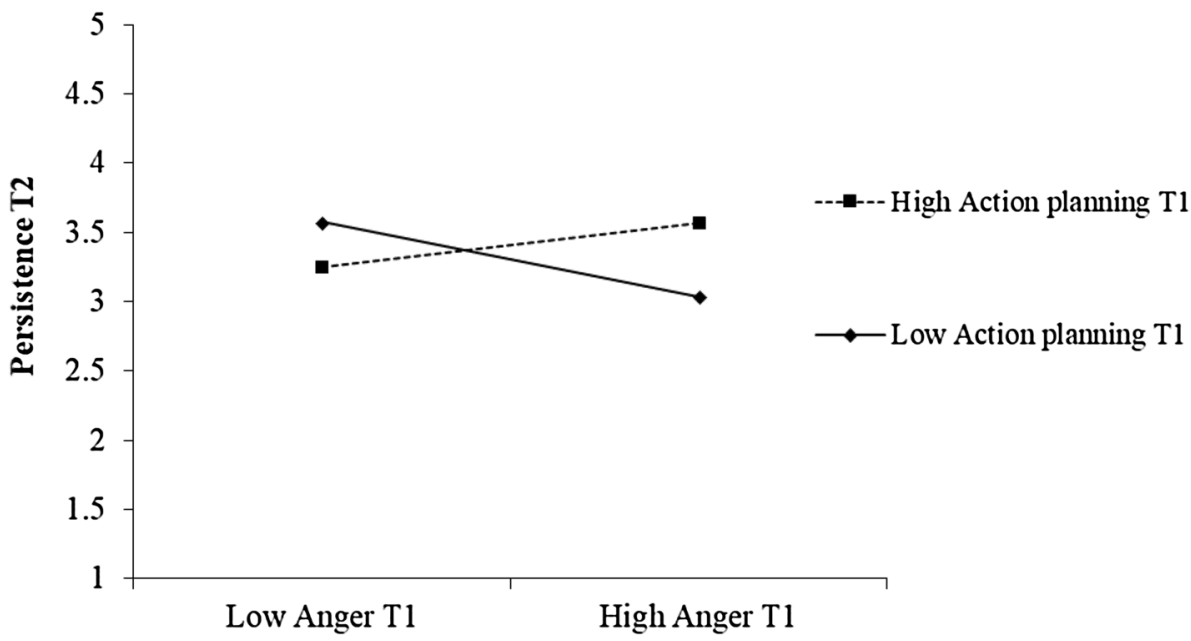

the interpretation of the statistically significant interaction (Dawson and Richter 2006; Jaccard et al. 1990). We examined the slopes at the 25th and 75th percentiles of the moderator. Action planning moderates the relationship between anger and persistence such that the relationship is negative for low levels of planning $(B=-0.15, S E=0.06, t=-2.48$, $p=0.014)$ and non-significant for high levels of planning $(B=0.05, S E=0.08, t=0.63, p=0.527)$. Thus, Hypothesis 1 is partly supported.

Hypothesis 2 states that action planning moderates the indirect effect of anger on goal achievement through persistence. We tested the conditional nature of the proposed mechanism depending on proactive action planning as the moderator and used conditional process analysis based on the PROCESS macro (Hayes 2013). The results are shown in the lower part of Table 2. The indirect effect was found to be negative for people low in action planning $(B=-1.79$, $S E=0.87,95 \%$ CI $[-3.39 ;-0.05])$ but it was non-significant when action planning was reported to be high $(B=0.58$, $S E=0.93,95 \%$ CI $[-1.10 ; 2.59])$. In summary, anger is negatively related to goal achievement through persistence when action planning is low, not when it is high. This result partly confirms Hypothesis 2 . Furthermore, Table 2 indicates that anger is not directly related to goal achievement at T2 $(B=-1.14, S E=1.30, t=-0.88, p=0.382)$.

Taken together, Study 1 illustrates the dysfunctional consequences of anger during goal pursuit for persistence and goal achievement when individuals did not develop action plans. One potential explanation is that when action planning is low, people tend to be easily distracted from the goal to be reached and they are unlikely to use their anger to engage in persistent, longer-term oriented behavior. Interestingly, and inconsistent with our hypothesis, under conditions of high planning, the experience of anger is not significantly related to persistence and goal achievement. Generating action plans does not necessarily help people to direct their feeling of anger towards persistent goal-oriented action.
To increase the confidence in the findings and to crossvalidate the results gathered from Study 1, a second study was undertaken which aimed at conceptually replicating the findings. Further, in this second study, we implemented two changes. First, we used a different measure for action planning that was based on a validated questionnaire instead of an open-question format. Second, we included a measure of persistence at $\mathrm{T} 1$ such that it was possible to control for the previous level of persistence when testing the hypotheses.

\section{Study 2}

\section{Method}

\section{Procedure and sample}

The procedure and design of Study 2 was identical to Study 1. Study 2 was conducted among both employees and students, who were recruited through personal contacts. Participants who responded at $\mathrm{T} 1$ were re-contacted 1 week later and were asked to fill in a second survey. The final sample of respondents who completed both surveys at $\mathrm{T} 1$ and $\mathrm{T} 2$ consisted of 119 participants (71 students and 47 employees). One respondent did not report his or her employment status. Participants' mean age was 30.22 years $(S D=13.23)$; one participant did not report his or her age. In total, $50.4 \%$ of our participants were female; two participants did not report their gender. Seven participants indicated that they had a middle school degree as their highest level of education, 49 had a high school degree, 37 had a Bachelor's degree, and 23 had a Master's degree. Three participants did not report their educational level. All respondents participated voluntarily and anonymously; we did not offer any incentives. 
Table 3 Means (M), standard deviations (SD), and correlations of Study 2 variables

\begin{tabular}{|c|c|c|c|c|c|c|c|c|c|c|}
\hline & & $M$ & $S D$ & 1 & 2 & 3 & 4 & 5 & 6 & 7 \\
\hline 1 & Age & 30.22 & 13.23 & - & & & & & & \\
\hline 2 & Employment status & 1.41 & 0.51 & $0.55^{* *}$ & - & & & & & \\
\hline 3 & Anger T1 & 2.19 & 1.24 & -0.08 & 0.02 & - & & & & \\
\hline 4 & Persistence T1 & 3.27 & 1.13 & 0.05 & 0.06 & -0.14 & - & & & \\
\hline 5 & Action planning $\mathrm{T} 1$ & 2.77 & 0.95 & 0.11 & 0.09 & 0.06 & $0.28 * *$ & - & & \\
\hline 6 & Goal achievement T1 (\%) & 39.00 & 27.12 & 0.04 & 0.06 & 0.06 & $0.22 *$ & $0.35^{* *}$ & - & \\
\hline 7 & Persistence T2 & 3.49 & 0.99 & 0.05 & $0.23 *$ & -0.18 & $0.49 * *$ & 0.18 & $0.20 *$ & - \\
\hline 8 & Goal achievement T2 (\%) & 63.03 & 31.42 & -0.04 & $0.20 *$ & $-0.20 *$ & $0.37 * *$ & 0.18 & $0.41 * *$ & $0.52 * *$ \\
\hline
\end{tabular}

$N=110-119$. Employment status was coded $1=$ student, $2=$ employee

$T$ Time

$* p<0.05 ; * * p<0.01$

\section{Measures at $\mathrm{T} 1$ and $\mathrm{T} 2$}

Similar to Study 1, we assessed our key constructs with single item measures and short scales. Anger at T1 and goal achievement at $\mathrm{T} 1$ and $\mathrm{T} 2$ were assessed with the same items as shown in Study 1. In addition, we measured persistence at both time points by using the same two items as in Study 1. The two items were correlated at T1 $(\rho=0.55, p<0.01)$ and at T2 $(\rho=0.44, p<0.01)$. In Study 2 , we measured action planning at $\mathrm{T} 1$ by using a self-rating. Specifically, we used three items based on the scale developed by Frese et al. (1987). The items were "I thought about several possible ways before working on my tasks.", "I had a plan B in mind in case something went wrong.", and "I made very detailed plans how to accomplish my tasks." The items were answered on a 5-point scale ranging from 1 (does not apply at all) to 5 (fully applies). Cronbach's alpha of the scale was 0.51 . Similar or even lower internal consistencies have been reported by Frese and colleagues (1987). We conducted an exploratory principle axis analysis using varimax rotation of the three items to examine their dimensional structure. The analysis identified one factor that explained $50.3 \%$ of total variance. Factor loadings were acceptable with 0.60 for item 2, 0.46 for item 3, and 0.45 for item 1 . The results suggest that the three items refer to slightly different aspects but they do still share a common characteristic and focus on action planning.

\section{Analyses}

We conducted the same analyses as in Study 1. To test our hypotheses, we applied multiple regression analysis and conditional process analysis by using the PROCESS macro (Hayes 2013). Again, we controlled for participant age, employment status, and goal achievement at T1 in our analyses. We further included persistence measured at $\mathrm{T} 1$ to control for the baseline and to model change in the mediator variable. Nine cases with missing data on any of the variables were deleted in the regression analyses, resulting in a sample size of 110 participants.

\section{Results and discussion}

Descriptive statistics and inter-correlations of the variables are presented in Table 3. Anger at T1 was unrelated to goal achievement at $\mathrm{T} 1(r=0.06, n s)$ and negatively related to goal achievement at T2 $(r=-0.20, p<0.05)$. Persistence at $\mathrm{T} 1$ was positively related to goal achievement at $\mathrm{T} 1$ $(r=0.22, p<0.05)$ and at T2 $(r=0.37, p<0.01)$. Persistence $\mathrm{T} 2$ was positively related to goal achievement at $\mathrm{T} 2$ $(r=0.52, p<0.01)$. Action planning was positively related to goal achievement at T1 $(r=0.35, p<0.01)$, but unrelated to goal achievement at $\mathrm{T} 2$.

Hypothesis 1 refers to the interaction effect of anger at $\mathrm{T} 1$ and action planning at $\mathrm{T} 1$ on persistence at $\mathrm{T} 2$. Table 4 shows that the interaction effect is significant $(B=0.14$, $S E=0.07, p=0.038)$. The increase of $R^{2}$ in persistence due to the interaction was $2.84 \%(F=4.44, p=0.038)$. This significant two-way interaction effect is depicted in Fig. 3. The simple slopes test revealed that the relationship was negative for low levels of action planning (25th percentile) $(B=-0.23, S E=0.08, t=-2.76, p=0.007)$, but non-significant for high levels of action planning (75th percentile) $(B=-0.05, S E=0.07, t=-0.62, p=0.538)$. This result indicates that Hypothesis 1 was partially supported in Study 2.

We tested Hypothesis 2 based on conditional process analysis (Hayes 2013) (see Table 4, lower part). Our analysis reveals a conditional indirect effect: anger was negatively related to goal achievement through persistence when individuals reported low action planning. The indirect effect was only significantly different from zero for low levels $(B=-2.40, S E=0.98,95 \%$ CI $[-4.29 ;-0.46])$, but not for high levels of action planning $(B=-0.47, S E=0.70,95 \%$ 
Table 4 Results of the conditional indirect effect hypothesis as based on conditional process analysis (Study 2)

\begin{tabular}{|c|c|c|c|c|c|}
\hline Predictor variable & $B$ & $S E$ & $95 \% C I$ & $t$ & $p$ \\
\hline \multicolumn{6}{|c|}{ DV: persistence T2 (mediator variable model) } \\
\hline Age & -0.01 & 0.01 & -0.02 to 0.01 & -1.13 & 0.262 \\
\hline Employment status & 0.42 & 0.19 & 0.03 to 0.80 & 2.16 & 0.033 \\
\hline Goal achievement T1 & 0.00 & 0.00 & -0.00 to 0.01 & 1.29 & 0.199 \\
\hline Anger $\mathrm{T} 1$ & -0.12 & 0.07 & -0.25 to 0.04 & -1.92 & 0.058 \\
\hline Persistence $\mathrm{T} 1$ & 0.38 & 0.08 & 0.23 to 0.54 & 5.00 & 0.000 \\
\hline Action planning T1 & 0.01 & 0.10 & -0.18 to 0.19 & 0.09 & 0.932 \\
\hline Anger $\mathrm{T} 1 *$ action planning $\mathrm{T} 1$ & 0.14 & 0.07 & 0.01 to 0.27 & 2.11 & 0.038 \\
\hline$R^{2}$ & 0.347 & & & & \\
\hline \multicolumn{6}{|c|}{ DV: goal achievement T2 (dependent variable model) } \\
\hline Age & -0.58 & 0.22 & -1.01 to -0.14 & -2.62 & 0.010 \\
\hline Employment status & 13.77 & 5.76 & 2.34 to 25.20 & 2.39 & 0.019 \\
\hline Goal achievement $\mathrm{T} 1$ & 0.36 & 0.09 & 0.17 to 0.54 & 3.86 & 0.000 \\
\hline Anger T1 & -3.64 & 1.95 & -7.50 to 0.21 & -1.87 & 0.064 \\
\hline Persistence T1 & 3.55 & 2.46 & -1.32 to 8.43 & 1.44 & 0.152 \\
\hline Action planning $\mathrm{T} 1$ & -1.70 & 2.85 & -7.35 to 3.94 & -0.60 & 0.551 \\
\hline Persistence T2 & 10.34 & 3.59 & 4.63 to 16.05 & 1.46 & 0.000 \\
\hline$R^{2}$ & 0.421 & & & & \\
\hline Action planning & Un & indirect effect & Boot $S E$ & Boot LLCI & Boot ULCI \\
\hline \multicolumn{6}{|c|}{$\begin{array}{l}\text { Conditional indirect effect at action plan- } \\
\text { ning }=25 \text { th and } 75 \text { th percentiles }\end{array}$} \\
\hline 25 th percentile & -2 & & 0.98 & -4.29 & -0.46 \\
\hline 75th percentile & -0 & & 0.70 & -1.87 & 1.00 \\
\hline
\end{tabular}

Listwise $N=110$. Unstandardized coefficients are reported. Variables that are used to calculate the interaction term (i.e., anger, action planning) were mean-centered prior to analysis. Bootstrap sample size $=5000$

$T$ Time, $D V$ dependent variable

Fig. 3 Two-way interaction of anger Time 1 and action planning Time 1 on persistence Time 2 (controlling for persistence Time 1) (Study 2)

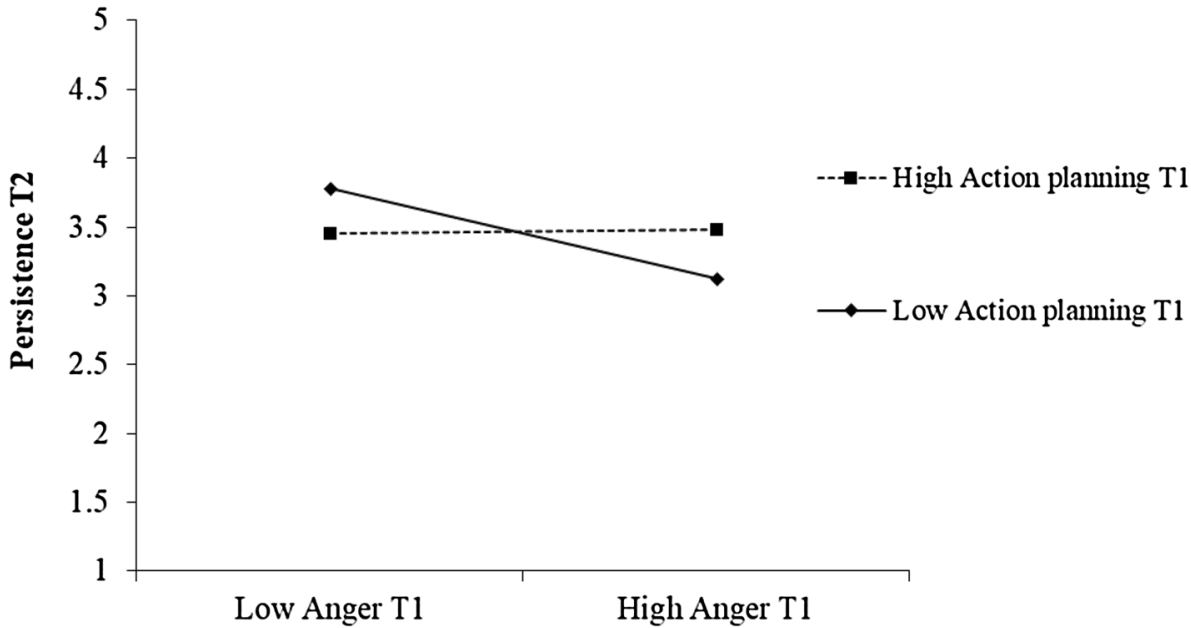

CI $[-1.87 ; 1.00])$. Hypothesis 2 was therefore partially supported. Moreover, the results as depicted in Table 4 indicate that there was no main effect of anger on individual goal achievement at $\mathrm{T} 2$ when controlling for goal achievement at $\mathrm{T} 1(B=-3.64, S E=1.95, t=-1.87, p=0.064)$.
In summary, the findings gathered from Study 2 on the moderating role of planning are similar to the findings reported in Study 1. Anger arising from inappropriate goal progress is negatively related to goal achievement through a decrease in persistence given that people missed generating strong action plans. However, the development of action 
plans does not ensure that anger during goal pursuit triggers persistence and goal achievement. ${ }^{1}$

\section{General discussion and implications}

The aim of this two-sample study was to examine when and why anger arising from goals being blocked or frustrated in the process of goal pursuit relates to the achievement of personal goals. Specifically, we focused on persistence on goal pursuit as a core mechanism linking anger and goal achievement. There are divergent perspectives in the literature on the relationship between anger, persistence, and goal achievement. On the one hand, theory and research suggests that anger may support persistence (Carver and HarmonJones 2009; Maglio et al. 2014; Seckler et al. 2017). On the other hand, anger may create an off-task focus such that regulatory resources are easily distracted from the goal and persistence is reduced (Beal et al. 2005; Kanfer et al. 1994; Seo et al. 2004). We argued for the role of action planning as a key boundary condition to explain these divergent perspectives. There is literature on the role of affect for goal pursuit and goal attainment (e.g., Carver and Harmon-Jones 2009; Harris et al. 2003; Pekrun et al. 2006; Seo et al. 2004), literature which shows that anger facilitates the formation and execution of action plans (Maglio et al. 2014), and research on the beneficial role of action planning for goal pursuit (e.g., Frese and Gielnik 2014; Frese et al. 2007; Gielnik et al. 2014; Gollwitzer 1999). However, we have relatively little knowledge on the interplay of anger as a discrete affective state and action planning for the achievement of personal goals. Here, we add to the knowledge by linking theory and research on affect with literature on motivation and the action regulation theory. The action regulation theory highlights the importance of high-quality action plans (i.e., self-initiated, future-oriented, detailed, and well-thought-out plans) as a means to bridge the gap between having a goal and instigating activities to accomplish it (Frese et al. 2007; Frese and Zapf 1994).

Across two field studies, our results show that the experience of anger is not directly related to individual differences

\footnotetext{
$\overline{1}$ To test the robustness of our findings and rule out the possibility that our results depend on previous goal progress, we tested whether the effect of anger is dependent on the extent to which individuals had achieved or progressed towards their respective goal at T1. We did not find support for such a contingency effect in Study $1(B=-0.01$, $S E=0.00, t=-1.67, p=0.096)$ or in Study $2(B=0.00, S E=0.00$, $t=0.73, p=0.466)$. Similarly, the interaction effect between anger and action planning was not dependent on goal achievement at T1 ( $B=0.11, S E=0.01, t=1.69, p=0.094$ for Study 1 and $B=-0.00$, $S E=0.00, t=-0.209, p=0.835$ for Study 2). Therefore, we conclude that the results do not depend on how much of the goal participants had already accomplished.
}

in the achievement of personal goals, but the relationship is mediated by persistence and moderated by action planning. This indicates that it is useful to study the mediation and moderation effects that underlie this relationship. Specifically, our results indicate that while there is no direct relationship between anger and persistence during goal pursuit, anger relates to a reduction of individual persistence and a decrease in goal achievement in case of low action planning. This finding supports the perspective that anger may potentially draw on people's regulatory resources as it requires a significant amount of attention and energy resources that may interfere with a task or goal (Beal et al. 2005). Once depleted, regulatory resources cannot be persistently invested by following one's plans and goals (Beal et al. 2005; Seo et al. 2004). Without a strong detailed and future-oriented action plan, there is a lack of orientation, structure, and guidance making it more difficult for people to maintain their way of acting and trying to accomplish their goals persistently when anger during goal pursuit arises (Frese and Zapf 1994; Lebel 2017; Parrott 2001).

These results may not be unique to the experience of anger but they apply to other negative affective states as well. According to Ellis and Ashbrook (1988) as well as Beal et al. (2005), all kinds of negative affective states have the potential to interfere with task performance as they draw on finite working memory capacity resources and, thus, diminish the cognitive resources that are necessary for goal pursuit. Detrimental effects may be stronger when affect intensity and arousal are taken into account such that activating affective states, for instance, anger or nervousness, are more likely to disrupt goal pursuit (Beal et al. 2005; Pekrun et al. 2006) than deactivating affect (e.g., boredom, sluggishness). Detrimental effects may also be stronger for selfrelevant affect (e.g., guilt, shame) that influence people's self-esteem and self-understanding (Weiner et al. 1979). Future research may thus consider studying the interplay of different negative affective states with action planning in order to examine whether our results on the role of action planning can be generalized to other affective states.

There was no support for the assumption that anger combined with detailed and future-oriented action plans increases people's persistence on working on their goals. In other words, action planning did not help people to direct their behavior to key activities in the goal achievement process through an increase in persistence. We argued that being angry because a goal is blocked or frustrated might signal and indicate a gap between the desired and the present state with regard to goal progress (Carver 2006; Schwarz and Clore 1983, 2003). The activation inherent in anger should help to reduce this discrepancy by engaging in more persistent behavior towards the goal when action plans are available (Carver 2006; Rucker and Petty 2004). However, for some goals, the level of energy or activation inherent in 
anger might not be needed; for these goals, anger should not affect individuals' level of persistence independent from the availability of action planning. For example, persistently engaging in routinized goals that require only a low amount of cognitive control may not depend on a high level of activation following the experience of anger because goal fulfillment is guided automatically (Frese and Zapf 1994; Wood and Rünger 2016). This may similarly apply to goals of low complexity or goals that are generally easy to achieve. Furthermore, individual differences with regard to goal-specific characteristics, such as subjective goal value or importance and goal commitment, might play a role (Locke and Latham 1990, 2002). If goal importance or commitment is low, the level of activation inherent in anger may not be instrumental for persistently engaging in this personal goal. Not only may the relationship between anger during goal pursuit and persistent goal striving be lower under these conditions, but previous research also reveals that in the case of low goal commitment, action planning does not have a significant supporting effect on goal achievement (Gollwitzer and Brandstätter 1997; Stadler et al. 2010).

As another explanation, and in line with research on the affective shift model (Bledow et al. 2011) and theory on functional affective dynamics (Kuhl 2001), the experience of anger as a negative activating affect might not be sufficient to promote persistent motivational behavior. Rather, people need to be also able to upregulate positive affective states (e.g., feeling enthusiastic) to enable motivated behavior such as persistence and, as a consequence, the attainment of personal goals. The upregulation of positive affect has a mobilizing function as it is associated with increases in expectancy motivation and goal commitment (Fishbach et al. 2010; Ilies and Judge 2005), which, in turn, should increase the persistence directed toward a certain goal.

\section{Practical implications}

Our results reveal that when people experience anger during goal pursuit because goals are blocked and goal progress is prevented, individuals' persistence is reduced given that they have not developed a strong action plan. This, in turn, will impair the level of goal achievement. Thus, planning is an essential boundary condition. People can be taught to develop action plans instead of just relying on their intuition in the pursuit of personal goals. For instance, research in the domain of entrepreneurship has shown that entrepreneurs benefit from training interventions that incorporate action planning as one main aspect. The evaluation of such a training concept demonstrated that participants increased their business success in terms of sales and profits after training in comparison to control groups that received no training or training unrelated to planning (Campos et al. 2017; Gielnik et al. 2015; Glaub et al. 2014).
Similarly, Raabe et al. (2007) developed and positively evaluated a career self-management training intervention based on action regulation theory to foster better career planning. Among other aspects to be trained, in this intervention participants were asked to develop a plan to direct career-related actions. To enhance the quality of planning, the plan was reviewed and criticized by other training participants and participants had to mentally simulate the steps mentioned in their plans to facilitate plan implementation. In addition, research by Gollwitzer and colleagues (Gollwitzer 1999; Gollwitzer et al. 2004) illustrates that individuals benefit from planning and thinking about conditions under which they will execute the intended behaviors (e.g., how, when, and where they will engage in the intended behavior) in order to pursue their goals.

In addition, persistently following one's goals and plans was found to act as a mediator in our model. Potential fruitful ways to foster persistence are to increase individuals' self-efficacy or their "can do" motivation (Parker et al. 2010) as well as to enhance their intrinsic motivation in the process of goal selection and goal pursuit (Deci and Ryan 2000).

\section{Limitations and implications for future research}

One limitation of the present study is that we used shortened and one-item measures to assess the main concepts. We were thus, in part, unable to provide information on the reliability of the measures used. However, we think that the use of these short measures is not much of a problem in the present study, as we focus on homogeneous and onedimensional constructs that are narrow in scope, and refer to a limited time span (Rossiter 2002; Wanous et al. 1997). Our approach is also in line with some previous studies that examined affective or goal-related concepts (e.g., Kuppens and Tuerlinckx 2007; Sheldon and Elliot 1998; Wanberg et al. 2010). Yet, future research should replicate our study with more extensive measures.

Second, the internal consistency of the three-item scale on action planning as used in Study 2 was low. A similarly low reliability was reported by Frese et al. (1987). This result might be attributed to the fact that action planning is reflected differently in various actions and domains, and it does not uniquely apply to all situations (Frese et al. 1987; Gielnik et al. 2014). Although they share a common theme, the three items seem to refer to slightly different aspects or content domains of action planning (e.g., developing detailed plans and creating back-up plans) that are not necessarily highly correlated (Frese et al. 1987; Gielnik et al. 2014; Parke et al. 2018). Future research needs to address the conceptualization and measurement of action planning (Edwards 2011; Parke et al. 2018). Accordingly, more comprehensive and valid measures are needed. 
Third, although we implemented two measurement points, the nature of the two studies precludes conclusions about causality because we did not have control over the variables and potential extraneous or confounding variables in our studies. Longitudinal research including more measurement points would be suitable (Wang et al. 2017). This approach would also help us to verify whether our findings referring to short-term goal achievement across a time horizon of one week can be transformed to longer-term goals and goal pursuit (Bateman and Barry 2012; Stadler et al. 2010). Moreover, the affective, motivational, and goal-related concepts we have measured are well-suited to be addressed in experimental or quasi-experimental study designs to increase the internal validity of the findings. As an optimal approach, researchers may manipulate both action planning as a boundary condition and persistence as a mediator (Gielnik et al. 2015; MacKinnon et al. 2007) in an experimental study design.

Fourth, in line with previous research and theory on motivation (Locke and Latham 1990; Seo et al. 2004), we argued that persistence in goal striving has positive consequences for the individual. However, this is a limited perspective. In certain instances (e.g., when a certain goal or action plan turns out to be dysfunctional), deciding to no longer pursue a personal goal and, therefore, disengaging from it may be a more effective strategy for the individual (Frese and Fay 2001; Heckhausen et al. 2010).

Future research may study other variables or boundary conditions that are missing in our model or that we have not focused on. For instance, we did not investigate the role of personality traits that might function as moderators in the relationship between the experience of anger during goal pursuit and persistence in goal striving. Personality differences in affect regulation might play a role in determining this relationship. Action-oriented individuals are better able to intuitively and implicitly regulate negative affective states such as anger as compared to state-oriented individuals (Koole and Jostmann 2004). Accordingly, for them it may be easier to handle the feeling of anger, increase their level of persistence, and, consequently, more effectively achieve personal goals independent of action planning.

Moreover, future research may study the moderating role of routines or routinized goal behavior in our conceptual model. Routines develop with repetition in a redundant environment. They require less effort and cognitive control (Frese and Zapf 1994). Routinized behavior basically serves the same function as action planning because it determines the processes and steps that are necessary to achieve a goal. Routinized behavior might help people to stay on track and ensure that certain goals are consistently followed over time, even when individuals experience negative emotions such as anger.

\section{Conclusion}

This research, which was based on two field studies shows that anger that is experienced in the process of goal pursuit, relates to a decrease in goal achievement through a decrease in persistent goal striving. This relationship occurs when individuals do not develop strong action plans. When people develop action plans, anger is not related to people's persistence and goal achievement.

Open Access This article is distributed under the terms of the Creative Commons Attribution 4.0 International License (http://creativeco mmons.org/licenses/by/4.0/), which permits unrestricted use, distribution, and reproduction in any medium, provided you give appropriate credit to the original author(s) and the source, provide a link to the Creative Commons license, and indicate if changes were made.

\section{References}

Aarts, H., Ruys, K. I., Veling, H., Renes, R. A., de Groot, J. H. B., van Nunen, A. N., \& Geertjes, S. (2010). The art of anger: Reward context turns avoidance responses to anger-related objects into approach. Psychological Science, 21, 1406-1410.

Bateman, T. S., \& Barry, B. (2012). Masters of the long haul: Pursuing long-term work goals. Journal of Organizational Behavior, $33,984-1006$.

Baumeister, R. F., Vohs, K. D., DeWall, C. N., \& Zhang, L. (2007). How emotion shapes behavior: Feedback, anticipation, and reflection, rather than direct causation. Personality and Social Psychology Review, 11, 167-203.

Baumeister, R. F., Vohs, K. D., \& Oettingen, G. (2016). Pragmatic prospection: How and why people think about the future. Review of General Psychology, 20, 3-16.

Beal, D. J., Weiss, H. M., Barros, E., \& MacDermid, S. M. (2005). An episodic process model of affective influences on performance. Journal of Applied Psychology, 90, 1054-1068.

Berkowitz, L., \& Harmon-Jones, E. (2004). Toward an understanding of the determinants of anger. Emotion, 4, 107-130.

Bhanji, J. P., \& Delgado, M. R. (2014). Perceived control influences neural responses to setbacks and promotes persistence. Neuron, 83, 1369-1375.

Bledow, R., Schmitt, A., Frese, M., \& Kühnel, J. (2011). The affective shift model of work engagement. Journal of Applied Psychology, 96, 1246-1257. https://doi.org/10.1037/a0024532.

Campos, F., Frese, M., Goldstein, M., Iacovone, L., Johnson, H. C., McKenzie, D., \& Mensmann, M. (2017). Teaching personal initiative beats traditional training in boosting small business in West Africa. Science, 357, 1287-1290.

Carver, C. S. (2006). Approach, avoidance, and the self-regulation of affect and action. Motivation and Emotion, 30, 105-110.

Carver, C. S., \& Harmon-Jones, E. (2009). Anger is an approachrelated affect: Evidence and implications. Psychological Bulletin, 135, 183-204.

Carver, C. S., \& Scheier, M. F. (1998). On the self-regulation of behavior. New York: Cambridge University Press.

Dawson, J. F., \& Richter, A. W. (2006). Probing three-way interactions in moderated multiple regression: Development and application of a slope difference test. Journal of Applied Psychology, 91, 917-926. 
Deci, E. L., \& Ryan, R. M. (2000). The "what" and "why" of goal pursuits: Human needs and the self-determination of behavior. Psychological Inquiry, 11, 227-268.

Diefendorff, J. M., \& Lord, R. G. (2003). The volitional and strategic effects of planning on task performance and goal commitment. Human Performance, 16, 365-387.

Edwards, J. R. (2011). The fallacy of formative measurement. Organizational Research Methods, 14, 370-388.

Eisinga, R., Grotenhuis, M., \& Pelzer, B. (2013). The reliability of a two-item scale: Pearson, Cronbach, or Spearman-Brown? International Journal of Public Health, 58, 637-642.

Ellis, H. C., \& Ashbrook, P. W. (1988). Resource allocation model of the effects of depressed mood states on memory. In K. Fiedler \& J. Forgas (Eds.), Affect, cognition, and social behavior: New evidence and integrative attempts (pp. 25-43). Toronto: Hogrefe.

Fishbach, A., Eyal, T., \& Finkelstein, S. R. (2010). How positive and negative feedback motivate goal pursuit. Social and Personality Psychology Compass, 4, 517-530.

Frese, M., \& Fay, D. (2001). Personal initiative (PI): An active performance concept for work in the 21st century. In B. M. Staw \& R. M. Sutton (Eds.), Research in Organizational Behavior (Vol. 23, pp. 133-187). Amsterdam: Elsevier Science.

Frese, M., \& Gielnik, M. M. (2014). The psychology of entrepreneurship. Annual Review Organizational Psychology and Organizational Behaviour, 1, 413-438.

Frese, M., \& Keith, N. (2015). Action errors, error management, and learning in organizations. Annual Review of Psychology, 66, 661-687.

Frese, M., Krauss, S. I., Keith, N., Escher, S., Grabarkiewicz, R., Luneng, S. T., Friedrich, C. (2007). Business owners' action planning and its relationship to business success in three African countries. Journal of Applied Psychology, 92, 1481-1498.

Frese, M., Stewart, J., \& Hannover, B. (1987). Goal-orientation and planfulness: Action styles as personality concepts. Journal of Personality and Social Psychology, 52, 1182-1194.

Frese, M., \& Zapf, D. (1994). Action as the core of work psychology: A German approach. In H. C. Triandis, M. D. Dunnette \& L. Hough (Eds.), Handbook of industrial and organizational psychology (Vol. 4, pp. 271-340). Palo Alto: Consulting Psychologists Press.

Gibson, D. E., \& Callister, R. R. (2010). Anger in organizations: Review and integration. Journal of Management, 36, 66-93.

Gielnik, M. M., Barabas, S., Frese, M., Namatovu-Dawa, R., Scholz, F. A., Metzger, J. R., \& Walter, T. (2014). A temporal analysis of how entrepreneurial goal intentions, positive fantasies, and action planning affect starting a new venture and when the effects wear off. Journal of Business Venturing, 29, 755-772.

Gielnik, M. M., Frese, M., Kahara-Kawuki, A., Katono, I., Kyejjusa, S., Munene, J., et al. (2015). Action and action-regulation in entrepreneurship: Evaluating a student training for promoting entrepreneurship. Academy of Management Learning \& Education, 14, 69-94.

Gielnik, M. M., Spitzmuller, M., Schmitt, A., Klemann, D., \& Frese, M. (2015). I put in effort, therefore I am passionate: Investigating the path from effort to passion in entrepreneurship. Academy of Management Journal, 58, 1012-1031.

Glaub, M., Frese, M., Fischer, S., \& Hoppe, M. (2014). Increasing personal initiative in small business managers or owners leads to entrepreneurial success: A theory-based controlled randomized field intervention for evidence-based management. Academy of Management Learning \& Education, 13, 354-379.

Gollwitzer, P. M. (1999). Implementation intentions: Strong effects of simple plans. American Psychologist, 54, 493-503.

Gollwitzer, P. M., \& Brandstätter, V. (1997). Implementation intentions and effective goal pusuit. Journal of Personality and Social Psychology, 73, 186-199.
Gollwitzer, P. M., Fujita, K., \& Oettingen, G. (2004). Planning and the implementation of goals. In R. F. Baumeister \& K. D. Vohs (Eds.), Handbook of Self-regulation: Research, Theory, and Applications (pp. 211-228). New York: Guilford Press.

Harris, C., Daniels, K., \& Briner, R. B. (2003). A daily diary study of goals and affective well-being at work. Journal of Occupational and Organizational Psychology, 76, 401-410.

Hayes, A. F. (2013). Introduction to mediation, moderation, and conditional process analysis: A regression-based approach. New York: Guilford Press.

Heckhausen, J., Wrosch, C., \& Schulz, R. (2010). A motivational theory of life-span development. Psychological Review, 117, $32-60$.

Ilies, R., \& Judge, T. A. (2005). Goal regulation across time: The effects of feedback and affect. Journal of Applied Psychology, 90, 453-467.

Jaccard, J., Wan, C. K., \& Turrisi, R. (1990). The detection and interpretation of interaction effects between continuous variables in multiple regression. Multivariate Behavioral Research, 25, 467-478.

Kanfer, R., Ackerman, P. L., Murtha, T. C., Dugdale, B., \& Nelson, L. (1994). Goal setting, conditions of practice, and task performance: A resource allocation perspective. Journal of Applied Psychology, 79, 826-835.

Kanfer, R., Chen, G., \& Pritchard, R. D. (2008). Work motivation: Past, present, and future. New York: Routledge.

Koole, S. L., \& Jostmann, N. B. (2004). Getting a grip on your feelings: Effects of action orientation and external demands on intuitive affect regulation. Journal of Personality and Social Psychology, 87, 974-990.

Kuhl, J. (2001). Motivation und Persönlichkeit: Interaktionen psychischer Systeme [Motivation and personality: Interactions of psychological systems]. Göttingen: Hogrefe.

Kuppens, P., \& Tuerlinckx, F. (2007). Personality traits predicting anger in self-, ambiguous-, and other caused unpleasant situations. Personality and Individual Differences, 42, 1105-1115.

Lebel, R. D. (2017). Moving beyond fight and flight: A contingent model of how the emotional regulation of anger and fear sparks proactivity. Academy of Management Review, 42, 190-206.

Lench, H. C., \& Levine, L. J. (2008). Goals and responses to failure: Knowing when to hold them and when to fold them. Motivation and Emotion, 32, 127-140.

Lerner, J. S., \& Tiedens, L. Z. (2006). Portrait of the angry decision maker: How appraisal tendencies shape anger's influence on cognition. Journal of Behavioral Decision Making, 19, 115-137.

Locke, E. A., \& Latham, G. P. (1990). A theory of goal setting and task performance. Englewood Cliffs: Prentice Hall.

Locke, E. A., \& Latham, G. P. (2002). Building a practically useful theory of goal and task motivation. American Psychologist, 57, 705-717.

MacKinnon, D. P., Fairchild, A. J., \& Fritz, M. S. (2007). Mediation analysis. Annual Review of Psychology, 58, 593-614.

Maglio, S. J., Gollwitzer, P. M., \& Oettingen, G. (2014). Emotion and control in the planning of goals. Motivation and Emotion, 38, 620-634.

Mikulincer, M. (1988). Reactance and helplessness following exposure to unsolvable problems: The effects of attributional style. Journal of Personality and Social Psychology, 54, 679-686.

O'Shea, D., Buckley, F., \& Halbesleben, J. R. B. (2017). Self-regulation in entrepreneurs: Integrating action, cognition, motivation, and emotions. Organizational Psychology Review, 7, 250-278.

Ohly, S., \& Schmitt, A. (2015). What makes us enthusiastic, angry, feeling at rest or worried? Development and validation of an affective work events taxonomy using concept mapping methodology. Journal of Business and Psychology, 30, 15-35. https://doi. org/10.1007/s10869-013-9328-3. 
Parke, M. R., Weinhardt, J. M., Brodsky, A., Tangirala, S., \& DeVoe, S. E. (2018). When daily planning improves employee performance: The importance of planning type, engagement, and interruptions. Journal of Applied Psychology, 103, 300-312.

Parker, S. K., Bindl, U. K., \& Strauss, K. (2010). Making things happen: A model of proactive motivation. Journal of Management, $36,827-856$.

Parrott, W. G. (2001). Implications of dysfunctional emotions for understanding how emotions function. Review of General Psychology, 5, 180-186.

Pekrun, R., Elliot, A. J., \& Maier, M. A. (2006). Achievement goals and discrete achievement emotions: A theoretical model and prospective test. Journal of Educational Psychology, 98, 583-597.

Raabe, B., Frese, M., \& Beehr, T. A. (2007). Action regulation theory and career self-management. Journal of Vocational Behavior, 70, 297-311.

Rossiter, J. R. (2002). The C-OAR-SE procedure for scale development in marketing. International Journal of Research in Marketing, 19, 305-335.

Rucker, D. D., \& Petty, R. E. (2004). Emotion specificity and consumer behavior: Anger, sadness, and preference for activity. Motivation and Emotion, 28, 3-21.

Schwarz, N., \& Clore, G. L. (1983). Mood, misattribution, and judgments of well-being: Informative and directive functions of affective states. Journal of Personality and Social Psychology, $45,513-523$.

Schwarz, N., \& Clore, G. L. (2003). Mood as information: 20 years later. Psychological Inquiry, 14, 296-303.

Seckler, C., Funken, R., \& Gielnik, M. M. (2017). Learning from entrepreneurial failure: Integrating emotional, motivational, and cognitive factors. In J. E. Ellingson \& R. A. Noe (Eds.), Autonomous learning in the workplace (pp. 54-77). New York: Routledge.

Seo, M.-G., Barret, F., L., \& Bartunek, J. M. (2004). The role of affective experience in work motivation. Academy of Management Review, 29, 423-439.
Sheldon, K. M., \& Elliot, A. J. (1998). Not all personal goals are personal: Comparing autonomous and controlled reasons for goals as predictors of effort and attainment. Personality and Social Psychology Bulletin, 24, 546-557.

Shrout, P. E., \& Fleiss, J. L. (1979). Intraclass correlation: Uses in assessing rater reliability. Psychological Bulletin, 86, 420-428.

Stadler, G., Oettingen, G., \& Gollwitzer, P. M. (2010). Intervention effects of information and self-regulation on eating fruits and vegetables over two years. Health Psychology, 29, 274-283.

Wanberg, C. R., Zhu, J., \& Van Hooft, E. A. J. (2010). The job search grind: Perceived progress, self-reactions, and self-regulation of search effort. Academy of Management Journal, 53, 788-807.

Wang, M., Beal, D. J., Chan, D., Newman, D. A., Vancouver, J. B., \& Vandenberg, R. J. (2017). Longitudinal research: A panel discussion on conceptual issues, research design, and statistical techniques. Work, Aging and Retirement, 3, 1-24.

Wanous, J. P., Reichers, A. E., \& Hudy, M. J. (1997). Overall job satisfaction: How good are single-item measures? Journal of Applied Psychology, 82, 247-252.

Watson, D., Wiese, D., Vaidya, J., \& Tellegen, A. (1999). The two general activation systems of affect: Structural findings, evolutionary considerations, and psychobiological evidence. Journal of Personality and Social Psychology, 76, 820-838.

Weiner, B., Russell, D., \& Lerman, D. (1979). The cognition-emotion process in achievement-related contexts. Journal of Personality and Social Psychology, 37, 1211-1220.

Wood, W., \& Rünger, D. (2016). Psychology of habit. Annual Review of Psychology, 67, 289-314.

Zacher, H., \& Frese, M. (2018). Action regulation theory: Foundations, current knowledge, and future directions. In D. S. Ones, N. Anderson, C. Viswesvaran \& H. K. Sinangil (Eds.), The SAGE handbook of industrial, work, and organizational psychology (Vol 2, pp. 80-102). Thousand Oaks: Sage. 